


\title{
Las improntas del escritor en la crítica literaria centroamericana: nociones recurrentes de autoría ${ }^{1}$
}

The impressions of the writer in the central american literary criticism: recurrent notions of authorship

\author{
Carlos Manuel Villalobos Villalobos ${ }^{2}$
}

Recibido: 4/3/2016 / Aprobado: 1/11/16

Resumen

\begin{abstract}
En este trabajo se analizan algunas de las nociones de autoría más recurrentes en la crítica literaria centroamericana. Se parte de las nociones idealistas de finales del siglo XIX, tales como las esbozadas por Rubén Darío y Gómez Carrillo. Se estudia cómo evolucionan los requisitos de la condición estética hacia requerimientos más éticos. Esto ocurre con el surgimiento del concepto del escritor comprometido y la exigencia, principalmente en el período de las sublevaciones bélicas, de que el autor debe escribir al servicio de una causa social. A finales del siglo XX e inicios del XXI, estos modelos entran en crisis y surge una nueva noción que tiene su origen en el marco del liberalismo y que busca, como proyecto hegemónico, canonizar modelos de representación literaria a través del recurso del diccionario. La última parte del artículo explora cómo se materializa en la región esta tarea enciclopédica y cuáles son los códigos que utilizan las respectivas catalogaciones.
\end{abstract}

Palabras clave: Crítica literaria, Literatura centroamericana, noción de autor, historiografía literaria, diccionarios literarios.

\section{Abstract}

This paper analyzes some of the most recurrent notions of authorship in the Central American literary criticism, and the idealistic notions from the late nineteenth century, such as those outlined by Ruben Dario and Gomez Carrillo. Also, it analyzes how the aesthetic conditions evolve towards more ethic requirements. This happens with the emergence of the concept of the committed writer and the demand, especially in the period of military uprisings that the author should write in the service of a social cause. In the late twentieth and early twenty-first century, these models change and a new concept emerges. This new concept has its origin in the framework of liberalism and as hegemonic project seeks to canonize literary representation models through the use of the dictionary. The last part of the article explores how the region is embodied in this encyclopedic work and what are the codes used in the respective categorizations.

Key words: Literary criticism, Central American Literature, notion of author, literary historiography, literary dictionaries.

\footnotetext{
${ }^{1}$ Este texto corresponde con la Conferencia inaugural presentada en el II Coloquuio Internacional de Investigación y Creación de la Cultura Artística Centroamericana, realizado el 9, 10 y 11 de setiembre de 2015, en el Museo Regional de San Ramón y en la Sede de Occidente, Universidad de Costa Rica, ahora en formato de artículo científico, en versión completa extendida.

${ }^{2}$ Profesor Catedrático de Teoría Literaria y Literatura, Escuela de Filología, Lingüística y Literatura, Universidad de Costa Rica. Doctor Interdisciplinario en Letras y Artes en Centroamérica con énfasis en Literatura. Correo electrónico: carlos.villalobos@ ucr.ac.cr
} 


\section{Introducción}

Al parafrasear los juegos dilemáticos de Borges, cabe preguntarse si es un yo o un nos-otros el que produce estas palabras. Se parte de la tesis de que en efecto no se está solo cuando "se cometen" estos actos discursivos. Valga esta acotación, pues es justo dejar constancia, como en el "Poema de los dones", la impronta colectiva que tiene el trabajo que continuación se presenta.

Los resultados de esta investigación no hubieran sido posibles sin los aportes de Magda Zavala y del consejo académico de Jorge Chen y Francisco Rodríguez, directora y asesores de un proceso académico, que culminó con una tesis de doctorado sobre el tópico de la crítica literaria en Centroamérica. En la pluralidad de "los dones advertidos” están también profesores como Werner Mackenbach y Mario Roberto Morales, entre otros; además de la complicidad de amigos y colegas de toda Centroamérica, quienes en su momento contribuyeron con documentos, recomendaciones y hasta con gratos recibimientos en sus países.

Se ha escogido para esta ocasión el tema del autor como elemento instituyente del fenómeno literario y se intentan rastrear algunas de las nociones de autoría más recurrentes en la historia de la literatura y la crítica literaria en Centroamérica. Sin embargo, hasta aquí, como se verá, son solo algunos atisbos. El tema permite dar cuenta, de manera aún mucho más amplia, de otros detalles de las continuidades y rupturas del proceso histórico. Así pues, esta será apenas una revisión más bien de exploración inicial. Se han seleccionado para esta tarea, de momento, cuatro anclajes que instituyen, desde la crítica literaria, diversos modos de entender la función de la autoría. Se inicia con las visiones idealistas de finales del siglo XIX y se continúa con la investidura ilustrada de los herederos de las preceptivas clásicas, también de finales del XIX y principios del XX. Luego se abordan los ideales románticos del autor y el compromiso social de los años sesentas y setentas del siglo XX y, finalmente, se consideran los nuevos roles autoriales como marcas de consumo y los procesos de legitimación canónica. Para esto, se finaliza con una somera revisión del fenómeno de los diccionarios centroamericanos producidos en los últimos años, cuya función instituyente es decisiva para la autorización y desautorización de los productores de textos literarios.

Como preámbulo es importante hacer notar algunas dificultades alrededor del concepto de autoría, pues las distintas nociones que ha manejado la crítica literaria centroamericana son en realidad ecos de ideas que han tenido lugar fuera de la región. Estas representaciones dialogan con herencias académicas donde ni siquiera en el universo supuestamente unívoco de Platón el autor tiene una silla estable. En el camino de este largo proceso, el autor ha sido idolatrado y despreciado. Algunas de las contribuciones que más han impactado el conocimiento han sido las aportaciones de Roland Barthes, Michael Foucault y Pierre Bordieu, entre otros. También, aunque no es el objetivo de esta investigación, las indagaciones sobre el autor implícito ofrecen un aporte que resultará valioso para entender algunas de las propuestas del discurso crítico. Dos de los enfoques más recurrentes son el de pacto autobiográfico de Philippe Lejeune (1975) y el concepto de autoficción de Manuel Alberca (2007).

María Amoretti, una de las investigadoras costarricenses que ha trabajo el tema, propone que normalmente se acepta que la figura del autor es una categoría dada, intemporal e irreductible; sin embargo, esta noción ha cambiado a lo largo de la historia. "Es esa solidez de entidad a priori, categoría dada de antemano, lo que hace de la noción de autor un concepto de manejo delicado, un ideologema fundante de la actual crítica literaria y emparentado con ciertas técnicas de subjetivación." (2002: 42). De este modo, esta noción es un efecto y una función del propio discurso. Según Amoretti: 
La imagen del autor es un constructo del propio discurso teórico de la literatura, pero coproducido al mismo tiempo por el funcionamiento del texto dentro de una práctica (institucionalizada), es decir, del hecho de que ese discurso escrito se pone a circular según determinados mecanismos sociales que regulan no solo su modo de producción, sino también su modo de distribución y consumo. (2002: 47).

Los postulados de la inmanencia textual y la autorreferencialidad del signo son dos nociones que en la teoría literaria contemporánea han reemplazado a la figura del autor; no obstante, la primacía del mercado editorial y la construcción de celebridades han mantenido el estatus del autor: "Lo que ha pasado es que se ha camuflado el significado real de su desaparición en aras de ese mismo mercado simbólico en el que la crítica literaria también obtiene dividendos." (2002: 48).

Estas dificultades también inciden en la historia de la cultura, pues la autoría no siempre ha sido un tema relevante. Existen obras canónicas que perdieron en el camino las marcas progenitoras; sin embargo, en la época actual las precisiones de la autoría, como decir, las certezas paternales, resultan un ejercicio complejo. No en vano el tema de los derechos de autor ha ido a parar a manos de las legislaciones, para decretar delitos e intentar resolver escándalos y jugadas comerciales alrededor de los supuestos creadores de cada asunto que existe en la cultura (hasta un simple revoltijo de frijoles con chicharrón es en el contexto costarricense objeto de discusiones y demandas judiciales).

En las vicisitudes de la historia se encuentran cientos de correcciones de autoría o escritos atribuidos equivocadamente a otros y polémicas aún no resueltas. De estas circunstancias no escapa la región que interesa en esta investigación. Se encuentran autores que firmaron con nombre de otros, como sucedió con el poeta ramonense Lisímaco Chavarría, quien firmó sus primeros libros con el nombre de su mujer; es conocida la disputa matrimonial que produjo este hecho. Hay también atribuciones dudosas o equívocos históricos, como es el caso de los poemas «La canción del invierno» $\mathrm{y}$ «Sonata», de Rafaela Contreras, atribuidos por error a Rubén Darío.

Capítulo aparte y tema para una investigación pendiente, están los numerosos seudónimos que han utilizado los escritores. Algunas de estas máscaras sin resolver permanecen hasta la fecha, así que las dubitativas por el tema de las autorías también forman parte de este espectro. A esto habría que agregar no solo la implicación semiótica del seudónimo, sino también las dinámicas circunstanciales que pueden estar atribuidas a juegos de poder, rasgos psicológicos o estrategias comerciales.

Para efectos metodológicos, esta investigación se aborda desde una perspectiva pragmática; por lo tanto, se intenta dar cuenta del proceso de la enunciación para decodificar cada uno de los modelos de autor abordados por la crítica literaria. Es decir, la pregunta de fondo consiste en determinar cómo se configura la figura del enunciador en el proceso de la comunicación literaria, y cómo la crítica literaria centroamericana ha interpretado $y$, al mismo tiempo, instituido esta función del proceso comunicativo.

Para precisar mejor esta inquietud se parte de la premisa pragmática de que en el proceso de la enunciación participan cuatro actores instituyentes: un enunciador, un mediador que es ocupado por los procesos de edición y propaganda, un enunciatario $\mathrm{y}$, finalmente, los instituyentes, como los críticos que tienen la función de legitimar; es decir, de canonizar ciertos textos y autores, incluidos los propios modelos de enunciación.

\section{El autor ungido: los amantes de la musa}

A finales del siglo XIX conviven dos imágenes autoriales que colocan a los autores centroamericanos en altares de prestigio: son principalmente el amante de la musa y el ilustre letrado.

Según la tesis de la inspiración, las musas, vestidas de deseo, buscan de almas sensibles. Los elegidos tienen la garantía de que su palabra viene de un afuera perfecto, donde la idea es pura 
e inmutable, según los resabios neoplatónicos. El autor es un ser distinto del común pues tiene el don de percibir los sutiles mensajes que le van dejando las musas que lo guían. Con su particular discurso diletante de crítico literario, Rubén Darío encuentra la palabra precisa para describir esta condición. Estos elegidos son seres raros. De ahí que su primer libro de comentarios literarios, publicado en 1896 se titule precisamente Los raros. Pero será más bien el guatemalteco Enrique Gómez Carrillo quien aparece en escena como uno de los instituyentes fundacionales de este modelo. En 1892, publica en Madrid un libro titulado Esquisses. Siluetas de escritores $y$ artistas. En este trabajo presenta, entre otros autores, a Oscar Wilde, Armand Silvestre, Paul Verlaine, Louis Le Cardonnel, Charles Morice, Alejandro Sawa y a su amigo Rubén Darío.

Un año después, Gómez Carrillo publica el libro Sensaciones de Arte, donde, entre otros temas, aborda la literatura japonesa, el neomisticismo e incluso reflexiona sobre el arte de la crítica. No obstante, la prioridad la siguen ocupando los retratos de autor. En esta oportunidad aparecen las anécdotas de visitas a Paul Varlaine y a Emilio Zolá. Uno de los capítulos se titula "Los siete maestros", donde presenta a los franceses Hippolyte Taine, Gustave Flaubert, Charles Baudelaire, Leconte de Lisle, Edmond de Goncourt y Stendhal.

Los autores son descritos normalmente con adjetivos de elogio sumamente elocuentes. Aplica a propósito de este hacer discursivo de los centroamericanos lo que Carlos Monsiváis señala en relación con la crítica mexicana de la misma época. El estudioso mexicano advierte que, en el contexto finisecular decimonónico, se puede concluir que la crítica literaria opera como un sistema de admiraciones mutuas, que edifica el culto a la palabra como garantía de civilización y certeza de lo moral. Se busca entonces halagar, "desatar la elocuencia lírica, convencer a los escasos lectores del sitio de honor de la fibra moral y su vínculo orgánico con las bellezas literarias." (1995: 1). Este aplauso implícito en el comentario fundacional de los estudios literarios en Centroamérica pocas veces es roto, dado el riesgo de las sanciones sociales que podría generar. Al igual que en el caso de México, como apunta Monsiváis, "solo unos cuantos desafían el pacto implícito del medio y censuran (el verbo y su carga moralista son inevitables) las debilidades estilísticas de un escritor, las brumas que acompañan su mensaje, las ocasionales repeticiones, los ripios" (1995: 2).

Así pues, frente al homenaje que le hace Gómez Carrillo a Rubén Darío, corresponde de vuelta por parte del nicaragüense otro elogio. En su libro Los raros, Darío mantendrá este mismo estilo laudatorio.

Además, si se considera que, desde el título mismo, se anuncia que se trata de una manera de presentar personajes denominados como "raros", es evidente que uno de los objetivos del texto es llamar la atención sobre la excepcionalidad de los autores. En Los raros desfilan Edgar Allan Poe, Leconte de Lisle, Paul Verlaine, El "Conde Lautréamont", Enrique Ibsen y Gabriel D’Annunzio, entre otros. Es importante recalcar que esta constatación inicial permite afirmar que la intención primera de Darío se fija en la primacía del autor como un sujeto diferente y genial. Es por ello, que además del énfasis en la descripción física de los autores, se esmera también por incluir aquellas anécdotas que lo vinculen personalmente con el autor en referencia. Darío no está interesado en dar cuenta de las obras en sí, el énfasis es el homenaje. Es explícito en este objetivo: "Vayan, pues, estas líneas como ofrenda del momento. Otra será la ocasión en que consagre al gran Verlaine el estudio que merece. Por hoy, no cabe el análisis de su obra." (1995: 47).

El enfoque presentado en estos ensayos, más allá de lucir su pluma lírica, es la puesta en discurso de sus asombros frente a figuras literarias influyentes. Es así como a propósito del Conde Lautréamont, advierte: "Si yo llevase a mi musa cerca del lugar en donde el loco está enjaulado vociferando al viento, le taparía los oídos." (1995: 49). Álvaro Urtecho, crítico nicaragüense, justifica este enfoque con el argumento de que Darío, en esta obra, no intenta una síntesis ordenada que establezca coordenadas literarias y culturales. Se trata de una crítica que parte de la intuición y la sensibilidad 
poética, pero con una información cultural orgánica y actualizada que le permite comprender los valores intrínsecos de la obra literaria y artística. Quien se asome a las páginas "de Los Raros comprobará que Darío, por encima del dramatismo exaltado, propio de la herencia romántica, con que retrata a sus poetas, persigue siempre la claridad, o sea, la verdad, los signos anunciadores de la época, la contemporaneidad" (2001: sp).

Sin embargo, Darío, y desde Luego Gómez Carrillo, idealizan en extremo al autor como una figura sobrehumana, es decir como un genio escogido para una misión trascendental. Por esto, precisamente, los escritores son seres "raros". Estas consideraciones tienen a la vez, de paso, una ganancia personal, pues si Gómez Carrillo y con más razón Darío son también escritores, el mecanismo de consagración aplica para ellos.

Como curiosidad, en el proceso de esta investigación se encontró un texto publicado en 1995 que mantiene encendida esta "vela idealista" decimonónica. Se trata del libro Literatura y literatos guatemaltecos de Hugo Cerezo Dardón, quien confiesa que "Preferí dejar prendidas en ellas la luz de mi afecto y la voz de la amistad, a sabiendas de ser extemporáneas para algunos lectores" (1995: nota introductoria).

Consciente de lo anacrónico, Cerezo Dardón se inclina por al estilo impresionista y procede a exaltar a sus autores dilectos, sobre todo aquellos que pertenecen a su círculo de amistades. Es el caso de la presentación que hace de su amigo Ricardo Estrada:

Su muerte ha enaltecido y perpetuado este vínculo, porque entonces, en el remanso de la serenidad y el recuerdo, solo veo en él la buena corteza de sus árboles; apreso la fuerza de su luz, revaloro su obra, la sitúo en su dimensión exacta, lo conozco mejor y más entrañablemente. (1995: 61).

\section{El autor autorirario: los letrados del poder}

La segunda variante de este modelo es la figura del escritor como un ilustrado de dotes culturales. En 1877, el nicaragüense Tomas Ayón había considerado que para garantizar la literatura, el autor debía contar con ciertas habilidades otorgadas por la "alta cultura". En relación con Centroamérica, la riqueza y la sonoridad del idioma castellano, unidos a la literatura española, ofrecen una ventaja. A esto añade que se cuenta "con la ardiente imaginación de los centroamericanos, enriquecida por las bellísimas perspectivas que a cada paso se presentan a la vista, y acariciada por la esperanza de un porvenir lleno de grandeza." (cit. por Delgado, 2002: 51). Los escritores son modelos de sabiduría, letrados de prestigio que al mismo tiempo suelen ser periodistas, políticos y diplomáticos.

En un análisis dedicado a la obra de Manuel González Zeledón, María Amoretti encuentra que la figura de Magón funciona como modelo de autoridad letrada. En Magón "la función autor tiene un peso extravagante, justamente en función del ejercicio de un poder textual que se demuestra en el talento de la manipulación efectiva del lector." (2002: 54). El cuento "El principio de autoridad" le sirve a Amoretti para analizar el juego discursivo producido entre el autor y narrador magoniano.

Así, el narrador autorial de Magón asume el principio de autoridad, en este relato y muchos otros, para cercar arbitrariamente la producción del significado y convertir la escritura en un espectáculo ante el cual el lector es solo una marioneta necesaria para poder simular la existencia de la comunicación, de un entendimiento compartido, cuando en realidad se trata de un entendimiento impuesto totalitariamente por el modo en que el relato se articula a partir de la presencia del autor. (2002: 61).

Entre los códigos estéticos que sustentaban estas figuraciones autoriales se encuentran las preceptivas literarias, dirigidas fundamentalmente al público escolar. Uno de los críticos con mayor autoridad académica de la primera mitad del siglo XX es el catedrático guatemalteco Enrique 
Muñoz, quien en 1951 recoge la trayectoria de su quehacer crítico bajo el título de Preceptiva Literaria. El texto da cuenta de los requisitos estéticos que debe cumplir la literatura. Al final, a modo de ejemplificación, incluye las biografías de algunos autores guatemaltecos. De este modo, establece, con base en sus postulados, un sistema de canonización. Los autores citados encajan en el modelo prescriptivo gracias a la autoridad del crítico. En este modelo del letrado culto, evidentemente, el crítico también ocupa un lugar sinónimo.

\section{El autor comprometido: la palabra y el fusil}

El modelo de investidura letrada se empieza a resquebrajar paralelo a diversos movimientos sociales, tales como las primeras huelgas bananeras, las huelgas de los brazos caídos (El Salvador, 1944; Costa Rica, 1948) y la Revolución Guatemalteca de 1944, entre otros hechos relevantes. Empiezan a aparecer líderes emblemáticos, héroes sociales que marcarán las nuevas ideologías: Farabundo Martí en El Salvador y César Augusto Sandino en Nicaragua.

Los escritores del nuevo siglo se contagian de estas fuerzas sociales y los instituyentes advierten de inmediato un nuevo papel por asignarle a los autores: el del escritor con consciencia que, a partir de una ética personal, se compromete con las causas sociales.

En 1972 la CEPAL convoca en San José un seminario latinoamericano denominado "El Escritor y el Cambio Social". En esta convocatoria se reúnen treinta y ocho escritores latinoamericanos que se proponen reflexionar sobre el proceso de cambio social y la contribución de la literatura. Como resultado se elaboró un documento titulado Reflexiones sobre el escritor en Latinoamérica y el cambio social (Usar la palabra como fusil). Tres años después, en esta misma ciudad se realiza el "Seminario Centroamericano sobre arte y sociedad". En dicha actividad se lanza un nuevo manifiesto claramente marcado por las posiciones marxistas del momento. Se propone que el arte debe producirse en función del grupo social y servir como mecanismo "desalienante". Se considera que es fundamental reconocer al pueblo como creador de cultura y lograr la participación activa de las masas en el quehacer cultural. En la agenda está la democratización de la cultura, pues ha sido negada al pueblo por las clases reaccionarias. Se propone recoger críticamente los mejores elementos de la cultura, para enriquecer la nacional (Uriarte, 2000: 48).

Uno de los estudios críticos que analiza la función de este modelo lo desarrolla el salvadoreño Rafael Lara Martínez a propósito del proceso escritural de Roque Dalton. Lara Martínez intenta explicar la producción literaria de este poeta, con base en consideraciones biográficas atinentes al proceso ideológico y creador. Así, en relación con el discurso novelístico de Dalton, Lara Martínez intenta indagar cómo se construyó en proceso productivo. Procura restituir un concepto más dinámico de la escritura, tal y como lo asumieron los postulados teóricos del postestructuralismo francés. El texto literario es visto como una productividad abierta e inacabada, integrada por un sinnúmero de referencias autónomas que están en constante ebullición. Según esta postura, antes de cualquier interpretación, el crítico debe "dar cuenta de las distintas etapas del libro póstumo por venir, de los borrones, de las adiciones y, en fin, de las contradicciones entre las varias versiones de algunos capítulos." (1999: 22).

Para desarrollar este trabajo, este crítico salvadoreño estudia cinco textos publicados que anteceden a la novela póstuma y un manuscrito inédito titulado Los poetas, mecanografiado en 1964. Los cinco textos antecedentes son: "Capítulos de Los poetas" (1965), Roque Dalton cuenta su evasión de la cárcel (1965), Creo que hay cosas que debo contar (1966), Conferencia de prensa (1967) y Una experiencia personal (1967). Estos textos funcionan como referencia "pre-escritural" a lo que supondría un texto definitivo publicado luego de su asesinato.

En este proceso, rastrea elementos textuales y extratextuales pertinentes para esta correlación pre-escritural. En relación con el manuscrito inédito

En este proceso, rastrea elementos textuales y extratextuales pertinentes para esta correlación pre-escritural. En relación con el manuscrito inédito 
Los poetas, Lara Martínez encuentra que el interés de este trabajo consiste en narrar la formación individual de varios escritores, así como la colectiva de un grupo artístico de vanguardia en el país. El vínculo entre la biografía de Dalton y la ficción se enmarca en la figura de distintos personajes que coinciden con aficiones o vivencias del autor. Uno de estos es un estudiante de derecho llamado Arturo. Para Lara Martínez, Arturo resume la experiencia personal del propio Roque Dalton en la Facultad de Jurisprudencia y Ciencias Sociales de la Universidad Nacional de El Salvador hacia finales de los años cincuenta. Arturo es aficionado al derecho criminal al igual que Dalton, quien en 1960 participa en la defensa de varios reos. Otro de los personajes es Álvaro, quien representa otra etapa daltiana: "Mientras Álvaro se investía como etnógrafo-poeta e historiógrafo-poeta, Arturo adopta una posición de notario-poeta." (1999: 33).

Más centrado en sí mismo es la referencia al personaje Roberto. Aquí el énfasis está puesto en los momentos de la niñez. Para el investigador, estas remisiones a la infancia plantean un dilema que puede verse como una contradicción entre el paradigma del compromiso político en la poesía y la necesidad de retornar a la infancia.

Tanto más contradictorio puede parecerme este retorno, cuanto que la niñez de Dalton la entendí gracias a tres rasgos que se contraponen a la militancia: la inconsciencia, traslucidez y enigma. Todo pasa entonces como si hubiese una brecha entre política y poética. Sin embargo, incluso después de 1964, la preocupación por la infancia seguirá siendo una de las temáticas claves de su poesía. (1999: 38).

El último proyecto literario que escoge el crítico salvadoreño para esta comparación tiene como personaje protagónico a Mario. En principio se trata de un diario personal que abarca desde el día de la independencia centroamericana, el 15 de septiembre, hasta el 25 de enero (1999:45). La identidad de este otro personaje coincide más con las visiones políticas de Dalton. Luego de este recorrido,
Lara Martínez concluye que, del manuscrito y las publicaciones examinadas,

solo el primero es tomado en consideración por las fechas que el autor póstumo asienta al final de la novela: "San Salvador 1964 La Habana 1971-1973”. Aunque esenciales para entender la etapa intermedia de "II. Roberto. Conferencia de prensa" y el origen autobiográfico de "V. José La luz del túnel", los otros cuatro textos, de 1965 a 1967, parecen irrelevantes y emparentarse con el borrón. Este olvido no solo nos informa de la infidelidad entre escrito posterior $y$ hechos pretéritos; a la vez, deja pendiente averiguar los eslabones que encadenan la versión original de Los poetas y la corrección póstuma. Mientras los archivos personales del escritor no han sido catalogados, de manera rigurosa, toda interpretación de su obra, al igual que la presente, no será sino un fragmento. (1999: 61).

Después de comparar los pretextos con el texto final, Lara encuentra que el proceso escritural en Dalton no procede de forma lineal, "siempre adquiere la figura de un múltiple engranaje conectando al menos un mecanismo dual." (1999:80). Considera que la imagen ideal de la propuesta literaria dalteana es un collage surrealista, no solo en esta novela, sino incluso en los trabajos que dedicó a la historia. Por otra parte, le llama la atención la reinvención del pasado siete años después del primer manuscrito, producto de su conversión ideológica revolucionaria. Dalton tacha la imagen del poeta maldito y bohemio, por la representación de un héroe bélico, comprometido socialmente. De este modo, "la conclusión original de la novela ha sufrido una tachadura; ha sido substituida por una teleología que privilegia el punto de cambio o la madurez política de una generación comprometida." (1999: 80-81).

La advertencia de este cambio muestra un proceso escritural que va de un texto original (1964) a un anclaje textual años después (1973). Esta indagación pretextual muestra que no existe 
versión final, sino distintas versiones que responden a diferentes condiciones simbólico-ideológicas del proceso autorial.

\section{Modelos de consumo: menú para degustar autores}

La última etapa de esta indagación se centra en los modelos de consumo que, desde finales del siglo XX, y hasta la fecha, interpelan a la figura del autor como parte de un catálogo de opciones. La cartilla del gusto se adecua a las filiaciones, redes de identidad y localismos, entre otros aspectos. Más allá de la historiografía que sitúa autores con base en clasificaciones generacionales o filiativas, el proceso discursivo que surge a finales del siglo XX busca ofrecer un catálogo de nombres que se diferencia de la sistematización de las producciones textuales o las cronologías historiográficas.

Es el caso del libro Biografías de siete grandes escritores guatemaltecos (1997) de Mario Alberto Carrera que se inscribe fundamentalmente en la práctica discursiva conocida como semblanza. En total, Carrera considera siete autores canonizados: Rafael Landívar, José Batres Montúfar, José Milla, Enrique Gómez Carrillo, Rafael Arévalo Martínez, Flavio Herrera y Miguel Ángel Asturias. Llama la atención el dato de que sean precisamente siete los autores seleccionados, (todos hombres, por cierto, lo que coincide con el carácter patriarcal de la literatura latinoamericana durante estos primeros siglos). El siete es simbólicamente un número significativo en la cultura occidental, pues representa la máxima realización (siete maravillas, siete espíritus, siete vidas...). De esto se puede deducir que los siete autores representan la consagración de la literatura guatemalteca. Ello coincide con la idea nacionalista, ya señalada, que forma parte del justificante motivador de una buena parte de las investigaciones literarias desarrolladas en Centroamérica.

La consagración canónica de estos escritores representativos de la literatura guatemalteca se une a los criterios puramente personales de Carrera, con base en la cercanía que él mismo tuvo, directa o indirectamente, con algunos de los autores incluidos. Esto le permite la confianza suficiente para denominarlos por apelativos amistosos, tales como "Pepe" en vez de José Milla o José Batres Montúfar (Pepe Batres), y más aún: los datos íntimos, sobre todo de carácter amatorio, son tema recurrente en estas semblanzas. De Flavio Herrera, por ejemplo, anota que durante su vida tuvo muchos amores: "Telma, Hortensia, Carmen, Anita, Elsa, Julieta; de las cuales y en el archivo de la Casa de la Cultura de la Universidad de San Carlos, se guarda vasta correspondencia sentimental." (1997: 99). Agrega que se casó dos veces y dos veces se divorció. A este dato añade que la primera de sus ex-esposas está recientemente fallecida y la segunda aún permanece viva. Esta misma indagación personal íntima es utilizada a propósito de Gómez Carrillo, el que también es presentado como un autor de numerosos amores: "fue famoso en el mundo entero por su pluma, su corazón y su espada”. A esto agrega inmediatamente que "a los 33 años aún no había entregado sus sentimientos a nadie de manera oficial. Esto es, ante el cura o el abogado" (1997: 58).

Estos datos, que quizá interesen más al ámbito del chismoteo, se saltan los consabidos de la crítica académica, sobre todo si se toma en cuenta que en el prólogo se advierte que uno de los objetivos es facilitar el conocimiento de la literatura nacional a los jóvenes de la población escolar. El libro pretende ser un compendio que contribuya con "los informes $y$ trabajos de la cátedra respectiva" (1997: prólogo). La referencia biográfica, sin embargo, pasa del modelo ejemplar de un niño llamado Arévalo Martínez que en la primera comunión pidió como regalo un libro de cuentos junto a una caja de soldados, a las vicisitudes amatorias que quizá no son tan pertinentes para el discurso escolar, sino para la curiosidad de los lectores en general. En todo caso, la razón principal de esta pesquisas de la intimidad la constituyen los criterios de la genialidad artística que se encuentra detrás de estas historias personales: uno de ellos, incluso, fue distinguido, nada más y menos que con el más prestigioso de los galardones mundiales: el premio Nobel. En el caso particular de Miguel Ángel Asturias, las circunstancias políticas inciden no solo en sus exilios, sino también en la producción de su obra. Por ello, Carrera les 
presta especial importancia a los juegos políticos de Guatemala para relacionarlos con la vida de Asturias, a quien cataloga como un revolucionario en todos los órdenes de la vida, pero sobre todo en lo político (1997: 118).

Estas semblanzas que van desde los detalles íntimos hasta el dato histórico-político de los autores concluyen con un recuento de los principales títulos de los autores. Estas listas de textos, que en el caso particular de Gómez Carrillo alcanzan los ochenta y seis, son las que justifican cada una de las siete biografías consignadas. Este trabajo de Mario Alberto Carrera es la antesala de un trabajo más minucioso que promueve la instituyente crítica. Se trata propiamente de la publicación de diccionarios de autores.

De acuerdo con las propuestas de Beatriz González, a propósito de historiografía literaria del liberalismo hispanoamericano, también la práctica del diccionario forma parte "la expresión orgánica del liberalismo, que, como proyecto ideológico de los sectores dominantes, canonizó modelos de representación histórico-literarios" (1987: 10). Así, al igual que la antología, la selección de autores propicia una estética dominante encargada de legitimar ciertos modelos discursivos e ideológicos y deslegitimar otros. Sin embargo, esta función legitimadora de autores, a partir del dato biográfico, no siempre ha encontrado una posición favorable entre las perspectivas críticas del área, sobre todo desde la postura de la crítica académica. Aunque no se discute que estos compendios cumplen una función necesaria, principalmente de carácter académico, críticos como Arturo Arias, opinan que "siempre le tuvimos reacciones alérgicas a las críticas enciclopédicas que sacaban listas y más listas de títulos de obras con algunos brevísimos esbozos biográficos del autor." (1998: 276). En esta línea, Arias reclama que estos trabajos carecen de comentario crítico reflexivo, y que en general plantean una escueta descripción de los contenidos de la obra.

Por su parte, el guatemalteco Carlos López defiende que el valor del diccionario radica en la posibilidad de solucionar la datación del acervo literario generado por una sociedad, de modo que se puedan responder preguntas claves en relación con las obras, tales como “¿Por qué dicen? ¿Quién habla desde el otro lado del texto? ¿Con quién dialoga?" (1993: 14). De acuerdo con esta premisa, la datación permite ubicar el productor de un texto literario en un contexto y en relación con un proyecto discursivo, de modo que le facilite al lector la ubicación de la obra.

El productor del diccionario selecciona autores bajo premisas similares a las que orientan las escogencias de los antologadores: el gusto personal, la cercanía y la investidura canónica. En palabras de José Francisco Ruiz Casanova, opera aquí un instinto de conservación de textos y de nombres, que "tiene también cierta dosis de prurito de recate de los autores" (2007: 39). Esta intención conlleva finalmente, al igual que en el caso de las antologías, una poética dominante; es decir, una construcción de nombres canónicos y, lógicamente al mismo tiempo, una negación de otros nombres o poética marginada.

Al igual que en las antologías, uno de los reclamos en el ámbito de las disputas de las poéticas marginadas se relaciona con inclusión de más voces masculinas en detrimento de las femeninas. En el ensayo Escrituras del yo femenino en Centroamérica 1940-2002, Teresa Fallas busca subsanar esta constatación, mediante el análisis de novelas autobiográficas, memorias, etnografías y testimonios autobiográficos, escritos por mujeres en Centroamérica. De este modo en la construcción de la propia subjetividad, las mujeres recurren a estrategias de enunciación que procuran el desmantelamiento de los códigos del poder patriarcal para rescatar la autoría femenina y al mismo tiempo inscribir el cuerpo como pertenencia, identidad y espacio de goce.

La mayoría de los diccionarios encontrados en la región en este contexto desconoce este cuestionamiento, excepto como se verá más adelante, las aportaciones del salvadoreño Carlos Cañas Dinarte. Los diccionarios de alcance centroamericano publicados hasta la fecha son básicamente tres: los dos primeros son del 
nicaragüense Jorge Eduardo Arellano, quien en 1997 publica el Diccionario de escritores centroamericanos y en el año 2003 edita una versión más actualizada, que titula Literatura Centroamericana. Diccionario de Autores Centroamericanos. Fuentes para su estudio ${ }^{3}$. El tercer proyecto corresponde al trabajo coordinado por el profesor costarricense Albino Chacón. Se trata del Diccionario de literatura centroamericana, publicado en el año 2007.

En cuanto a los diccionarios de carácter nacional, la lista es más extensa, pero solamente existen publicaciones para Guatemala, El Salvador y Honduras. En Guatemala la primera publicación de este tipo es el Diccionario de autores guatemaltecos de Francisco Albizúrez Palma de 1984. En 1993 Carlos López divulga un trabajo mucho más amplio que el de Albizúrez. Se trata del Diccionario biobibliográfico de literatos guatemaltecos. Una de las novedades de esta obra son las reflexiones sobre el trabajo de selección de las obras y la literatura guatemalteca en general; en total, consigna un poco más de trescientos cincuenta autores y ofrece un facsímil de la portada de algunas de las óperas primas más relevantes de la literatura guatemalteca.

López insiste en que "un diccionario es una herramienta de consulta, que no necesariamente confirma la regla de la historia ni de la teoría literarias" (1993: 16). Para esta clasificación, utiliza como método de trabajo la consignación de la obra publicada, y en algunos casos de la inédita en sucesión cronológica.

El propósito enciclopédico sigue vigente en este tipo de abordajes. No es extraño que López establezca que "este diccionario pretende ser un armario en el que se guarde intemporalmente, inalterable en su clasificación, una materia fugitiva" (1993: 20). Este proyecto, que aspira a la perennidad, muestra además una intención nacionalista que el propio López no niega en el prólogo. Plantea que "Este trabajo tiene dentro de sus objetivos contribuir a la conservación y difusión del patrimonio literario guatemalteco" (1993: 23).

Esta misma intención nacionalista es la que explica el anexo clasificatorio de los autores guatemaltecos mediante una sui generis taxonomía, que diferencia entre escritores que han sido presidentes de repúblicas (Antonio José Irisarri en Chile y Juan José Arévalo en Guatemala); aquellos autores que han tenido cargos menores dentro del gobierno y los que han recibido premios (1993: 22).

La relación estado nacional y escritor; sin embargo, es particularmente negativa desde la óptica del escritor Marco Antonio Flores, quien elabora una presentación del diccionario. Para Flores, el criterio político ideológico ha funcionado como mecanismo para incluir o excluir a los escritores. Indica que durante la década de los 80 el proceso de exclusión fue tan agudo que llegó a determinarse, incluso, por parte de los sectores represivos, que todos los escritores eran peligrosos ideológicamente. Esto obligó a la gran mayoría de los autores de este país a escribir en el exilio. Los que han permanecido en el territorio "han frustrado su vocación o carecen de seriedad y disciplina porque las condiciones sociales, políticas y económicas les son adversas" (López, 1993: 11).

En el Salvador destaca el trabajo de Carlos Cañas-Dinarte, originalmente publicado en 1998 como Diccionario escolar de autores salvadoreños. Una propuesta ampliada fue publicada en el año 2002, bajo el título de Diccionario de autoras $y$ autores de El Salvador. De acuerdo con el autor, el propósito de este diccionario es reunir información acerca de las escritoras y los escritores de El Salvador, de modo que oriente a estudiantes e investigadores académicos. Tiene también una intención de enmienda y actualización de muchos de los datos que circulaban previamente en relación con algunos de los autores. "La idea principal fue reunir en un mismo volumen la mayor cantidad de

\footnotetext{
${ }^{3}$ Una de las particularidades de este trabajo es la imprecisión o datos inconclusos, que evidencian el carácter de "proceso" de este proyecto. Sin embargo, el diccionario está concebido como "fuente documental", de modo que pueda facilitar la tarea indagatoria a otros investigadores.
} 
datos biográficos sobre nuestras cultoras y cultores de todos los campos de las letras." (2002: 11).

Cañas-Dinarte es experto en archivística y ha trabajado en periódicos salvadoreños y en asesorías en la búsqueda de datos históricos, principalmente sobre su país. Esto explica, en parte, la metodología seguida para abordar el diccionario biográfico. Cada una de las presentaciones es meticulosa en datos curriculares y bibliográficos. La consignación exacta del día de nacimiento suele coincidir con datos familiares como son el nombre y la profesión de los padres. Los datos escolares y laborales, así como algún otro aspecto relevante como permanencia fuera del país u otras actividades realizadas durante la vida forman parte de los datos que permiten organizar cada una de las fichas biográficas. La rigurosidad en el manejo de los datos incluye precisiones relacionadas con anécdotas de carácter obituario. Por ejemplo, en relación con Antonio Gamero anota:

En los meses finales de su vida se trasladó a San Salvador para permanecer al lado de su anciana y viuda madre, aunque él mismo ya se encontraba muy enfermo de neumonía. Murió en la capital salvadoreña, a las 18:30 horas del domingo 20 de octubre de 1974, víctima de un ataque cardíaco originado en su agravada enfermedad. Sus restos mortales fueron trasladados al barrio Belén de Nueva San Salvador, donde fueron velados antes de ser conducidos al camposanto local. (2002: 194).

Uno de los aspectos que Cañas-Dinarte aborda con precaución es el relacionado con la inclusión de género. Aunque por una razón de carácter histórico-patriarcal, hay más hombres que mujeres, en el título, al hacer la diferencia entre autoras y autores, procura dar cuenta de esta inclusión. Otro aspecto inédito en la historia del diccionario literario centroamericano es la consignación de datos bibliográficos de fuente cibernética. Al final de varias de las fichas incluye algunas direcciones de Internet donde el lector podría encontrar más información de los autores salvadoreños.
Honduras es el país del área que cuenta con un mayor número de incursiones en el diccionario de escritores. Los principales exponentes han sido Mario Argueta, José González y Nery Alexis Gaitán. En 1993, Mario Argueta publica una obra titulada Diccionario crítico de obras literarias hondureñas. Se trata de una perspectiva, hasta el momento, única en el área. Las entradas alfabéticas se establecen en función del título de los libros. Este trabajo rompe con el énfasis autorial que tradicionalmente desarrolla el diccionarista literario. Según Argueta: "Nuestro propósito se limita a ofrecer ayuda al lector una vez que haya concluido la lectura de la obra correspondiente. Al finalizar ambas actividades, logrará formular sus propias conclusiones" (1993: 17).

En 1998, Argueta continúa su trabajo diccionarista y, esta vez, lo dedica exclusivamente a los autores. Al igual que en el libro anterior, reúne diferentes comentarios que, sobre los escritores referidos, han escrito los propios autores o críticos literarios. Estas citas no incluyen las referencias bibliográficas. Los apuntes biográficos son sumamente sinópticos. Por ejemplo, a propósito de Carlos Elvir Aceituno, únicamente apunta: "Nació en San Juancito (1921). Optometrista. Obra: Laberinto Dorato (1996." (1998:75). Este estilo le permite ser sumamente inclusivo, al punto que la cantidad de entradas ronda las 500. Sin embargo, algunos autores, mayormente legitimados, como es el caso de Óscar Acosta, Ramón Amaya, Medardo Mejía o Juan Ramón Molina ocupan varias páginas con extensas citas. Esta diferenciación entre la referencia casi telegráfica y las extensas citas establecen una distinción que legitima a unos autores más que a otros, lo que hace que se perpetúe la lista vigente de los autores canonizados.

Por su parte, José González en su libro Diccionario de literatos hondureños (1997) ofrece una breve biografía de un poco más de ciento cincuenta autores. De algunos de ellos, al igual que lo hace Argueta, solo incluye unos cuantos datos biográficos y bibliográficos. Por ejemplo, de la poeta Xiomara Bu únicamente apunta: "Poeta. Realizó estudios de Filosofía en Honduras y EEUU. Es investigadora de 
algunos organismos internacionales y profesora de planta de la carrera de Filosofía de la UNAH" (1977: 29). Acto seguido apunta el género y título de dos de sus obras. Este tipo de fichas escuetas abundan en el diccionario, el que finalmente constituye un pequeño compendio de referencias básicas. A diferencia de Mario Argueta, carece de citas textuales y mantiene, en general un equilibrio, cuantitativo y cualitativo en cada una de las entradas.

Un trabajo particular es el que elabora Nery Alexis Gaitán en 1998. Se trata del Índice de cuentistas hondureños, que como su nombre lo indica está dedicado exclusivamente a autores que han cultivado el relato corto. Contiene fichas biográficas abreviadas de alrededor de ochenta autores. Al igual que el diccionario del nicaragüense Jorge Eduardo Arellano, el texto de Gaitán se caracteriza por la imprecisión en algunos datos, solo que en este caso, la síntesis se aplica a todos los autores. Algunas de las entradas son breves: de Álvaro Cerrato consigna: "Nació (?) (sic) Murió en 1972. Obra: Páginas rojas (1933), con prólogo de Marcos Carías" (1998: 16). Aún más resumida es el dato que aporta de Gustavo Chirinox: "Obra: Cuentos de amor de pasión y dolor (1932).” (1998: 16).

Una particularidad, en general, de este trabajo en Centroamérica es la configuración de la ficha curricular que pretende servir de información básica al investigador. Opera aquí, al igual que en los procesos de filiación literaria, la impronta que dejó en la región centroamericana la perspectiva positivista de destacados estudiosos literarios, como por ejemplo el francés Hippolyte Taine (1828-1893) o el norteamericano René Wallek (1903-1995) y el checo-americano Austin Warren (1899-1986) ${ }^{4}$.

La voluntad enciclopédica de estos diccionarios se justifica, principalmente, mediante argumentos de carácter nacionalista. Es por ello, probablemente, que lo que más interesa es el dato curricular y no la relación de análisis discursivo autor-texto, que podría resultar mucho cercana al ejercicio de la crítica literaria. Una excepción a esta idea se puede encontrar en el diccionario propuesto por el hondureño Mario Argueta; sin embargo, en este caso, las referencias son citas textuales de otros estudiosos, elaboradas para otro propósito.

Un aspecto relevante que se subyace en la decisión de privilegiar determinado autor $\mathrm{u}$ obra se vincula con el tema del canon literario. El diccionario se construye con base en los parámetros de aceptación que posee previamente el proponente y a la vez incide en los procesos de legitimación ulterior. En otras palabras, en el canon literario participan factores de carácter estético y críticos, y además, factores institucionales, pedagógicos, entre otros (Ruiz, 2007: 147), que inciden, como ya se apuntado anteriormente, en una poética dominante. Así pues, si bien el canon se determina por ciertos verosímiles estéticos vigentes en un contexto dado, también se moldea gracias las posibles condiciones de circulación y consumo. De acuerdo con Pierre Bourdieu, las estrategias de los agentes y de las instituciones que están comprometidos con las luchas literarias o artísticas no se definen en la confrontación pura, sino que dependen de la posición que ocupen en la estructura del campo, "es decir en la estructura de la distribución del capital específico, del reconocimiento, institucionalizado o no, que les es concedido por sus pares-competidores o por el gran público" (1995: 309).

De este modo, la lucha por la imposición de ciertos nombres y la exclusión de otros se evidencia en la cantidad de entradas y consideraciones de cada uno de los diccionarios. Hay autores excluidos, o bien, marcas que muestran mayor o menor interés, por lo general asociadas a la cantidad de espacio dedicado. Igualmente, como ocurre con el diccionario que propone Carlos Cañas Dinarte, el canon puede estar marcado con la decisión consciente de incluir voces femeninas, frente al resto de diccionarios que claramente privilegian un canon tradicionalmente masculinizado.

Estos catálogos surgen como novedad reciente en la historia de los instituyentes centroamericanos.

\footnotetext{
${ }^{4}$ Wallek y Warren publican en 1949 A Theory of literature, un libro de reiterada referencia en las academias de la región.
} 
Responden también a una condición pragmática que sabe que el consumo de nombres autoriales ofrece mayor garantía de acceso a una sistematización general de la literatura centroamericana o las literaturas nacionales. En la dimensión ilocutiva subyace la legitimación canónica del consumo. Es un menú de entradas para que el interesado se informe, conforme a su gusto.

\section{Otros anclajes autoriales pendientes: conclusiones}

Hasta aquí, a modo de un somero recorrido histórico, se han planteado cuatro momentos fundamentales de la crítica literaria de Centroamérica, para explorar las representaciones de autoría vigentes en cada uno de los momentos. Cada uno de estos anclajes responde a visiones de mundo particulares y desde ahí se legitima una imagen específica del autor y su función discursiva. Los escritores son genios perseguidos por la musa, modelos letrados de la nación, héroes sociales en las luchas de clases o un menú de biografías para el consumo de los gustos.

Estas cuatro imágenes, aunque relevantes, sin embargo, no son las únicas, tanto desde el punto de vista de la enunciación crítica de la región, como desde un posible enfoque propiamente de la enunciación literaria.

Es posible adentrarse en la literatura colonial y determinar cómo se enunciaba entonces la figura autorial. Ya en el siglo XIX, en el período nacional, las publicaciones periódicas empiezan a evidenciar algunos rasgos que igualmente podrían ser objeto de futuras indagaciones. Por ejemplo, en El Salvador, el presbítero Juan Bertis (1837-1899) ${ }^{5}$ inauguró la Cátedra de Literatura en la Universidad de El Salvador y, entre otros temas, escribió sobre tópicos literarios con base en los lineamientos de la escolástica (Gallegos, 1981: 157). Una línea de trabajo sugerente sería preguntarse, desde estos escritos, cómo funciona el sujeto autorial bajo la óptica del enunciado escolástico.
Otro de los pendientes para continuar con este trabajo consistiría en mirar cómo se configuró el dilema del sujeto autorial en la dinámica de la literatura testimonial, pues es evidentes que se rompe con el modelo tradicional. En este caso un informante cuenta a un mediador que sistematiza la información. Aunque ambos nombres aparecen consignados no resulta claro cómo se concreta en este caso la legitimación o el alcance autorial. La ventaja de este pendiente es que existe una polémica ampliamente divulgada que posiblemente ofrezca algunas claves.

Igualmente como se sugirió al inicio, queda pendiente para una investigación más amplia el tratamiento del concepto de lector implícito, donde se podrían considerar con más detalle las autorreferencias, los juegos de la autoficción o los procedimientos del pacto autobiográfico. Es decir, habría que averiguar si estas posibles coincidencias del sujeto de la enunciación con el sujeto del enunciado responden también a estos mismos modelos de autoría y cómo se materializan; o bien, si es posible identificar otras marcas que responden a nuevas instituyentes.

Se concluye con la inquietud de que el derecho de autor funciona bajo las mismas premisas de la propiedad privada. El plagio, la cita sin fuente, la copia camuflada y otros miedos de la época han hecho que los escritores en vez de seres raros dotados de genialidad, en vez de héroes que caminan con la espada revolucionaria, se hayan convertido en vendedores ambulantes que luchan por un espacio comercial en la mirada de los otros. Mientras caminan los acosa el miedo de que en un robo callejero alguien les arrebate la última metáfora que inventaron. Sin embargo, habría que regresar a Borges y más aún al riesgo de Roland Barthes con sus teorías sobre la muerte del autor, pues la palabra es inevitablemente social y las ideas son un tejido que de algún modo ya tejió el sistema de representaciones.

\footnotetext{
${ }^{5}$ Los trabajos críticos de Bertis fueron publicados en formato de libro hasta 1941 bajo el título de Ciencia y Literatura.
} 


\section{Bibliografía}

Alberca, M. (2007). El pacto ambiguo. De la novela autobiográfica a la autoficción. Prólogo de Justo Navarro. Madrid: Editorial Biblioteca Nueva.

Amoretti, M. (2002). Magón... la irresistible seducción del discurso. San José, Editorial Perro Azul.

Arellano, J. (2003). Literatura Centroamericana. Diccionario de autores centroamericanos. Managua: Fundación Vida.

Argueta, M. (1993).Diccionario crítico de obras literarias hondureñas. Tegucigalpa: Editorial Gaymuras.

Argueta, M. (1998).Diccionario de escritores hondureños. Tegucigalpa: Editorial Universitaria.

Arias, A. (1998). Gestos Ceremoniales. Narrativa centroamericana 1060-1990. Guatemala, Artemis Edinter:

Bourdieu, P. (1995). Trad. Tomas Kauf. Las reglas del arte. Génesis y estructura del campo literario. Barcelona: Editorial Anagrama.

Cañas, C. (2002).Diccionario de autoras y autores de El Salvador. San Salvador: Dirección de publicaciones e impresos.

Carrera, M. (1997). Biografías de siete grandes escritores guatemaltecos. Guatemala: Artemis \& Edinter.

Chacón, A. (coord.). (2007). Diccionario de la literatura centroamericana. San José, Heredia: Editorial Costa Rica, Editorial Universidad Nacional.

CEPAL. (1973).El escritor y el cambio social. San José: Litografía Lehmann.

Cerezo, H. (1995). Literatura y literatos guatemaltecos. Guatemala: Editorial Artemis.
Darío, R. (sf). Retratos y figuras Colección "La expresión Americana” Caracas: Editorial Torino.

Delgado, L. (2002). Márgenes recorridos. Apuntes sobre procesos culturales y literatura nicaragüense del siglo XX. Managua, Instituto de Historia de Nicaragua y Centroamérica.

Fallas, T. (2013). Escrituras del yo femenino en Centroamérica 1940-2002. San José, Costa Rica, Editorial de la Universidad de Costa Rica.

Gaitán, N. (1998). Índice de cuentistas hondureños. Tegucigalpa: Editorial Universitaria UNAH.

Gallegos, L. (1981).Panorama de la literatura salvadoreña. Del período precolombino a 1980. San Salvador: U.C.A. Editores.

González, B. (1987). La historiografía literaria del liberalismo hispanoamericano del siglo XIX. Habana, Casa de las Américas.

González, J. (1997). Diccionario de literatos hondureños. Tegucigalpa: Editorial Guaymuras.

Lara, R. “Roque romántico. De la teoría literaria como simulacro de historia. El caso de una novela póstuma de Roque Dalton." En LaraMartínez y Seager (Eds.) (1999). Los Otros Roques. Ensayos sobre la poética múltiple de Roque Dalton.New Orleans: U. P. of the South.

Lejeune, P. (1994). El pacto autobiográfico y otros estudios. Madrid: Megazul-endymión.

López, C. (1993). Diccionario bio-bibliográfico de literatos guatemaltecos. México: Editorial Praxis.

Monsiváis, C. (1995). La crítica literaria en México: la invención, la revisión, la ampliación y el olvido del canon. Nuevo texto crítico, Número 14/15. 
Muñoz, E. (1951). Preceptiva literaria. Guatemala: Editorial del Ministerio de Educación Pública.

Ruiz, J. (2007). Anthologos. Poética de la antología. Madrid: Cátedra.

Uriarte, I. (2000). La poesía de Ernesto Cardenal en el proceso social centroamericano. Managua: Centro Nicaragüense de Escritores,

Urtecho, A. (enero, 2001). Rubén Darío como crítico literario Indagaciones en torno a LOS RAROS. En Bolsa Cultural Ed. 173-26. Recuperado de http://www.grupoese.com.ni/ 2001/bn/bc/ ed173/ruben173.htm 